University for Business and Technology in Kosovo

UBT Knowledge Center

UBT International Conference

2015 UBT International Conference

Nov 7th, 9:00 AM - 5:00 PM

\title{
Prepaid Meter Management System Challenge for Albanian Power Distribution Operator-OSHEE
}

\author{
Genci Sharko \\ Polytechnic University of Tirana, gsharko@gmail.com \\ Anni Dasho Sharko \\ European University of Tirana, anidasho@gmail.com
}

Follow this and additional works at: https://knowledgecenter.ubt-uni.net/conference

Part of the Engineering Commons

\section{Recommended Citation}

Sharko, Genci and Sharko, Anni Dasho, "Prepaid Meter Management System Challenge for Albanian Power Distribution Operator-OSHEE" (2015). UBT International Conference. 44.

https://knowledgecenter.ubt-uni.net/conference/2015/all-events/44

This Event is brought to you for free and open access by the Publication and Journals at UBT Knowledge Center. It has been accepted for inclusion in UBT International Conference by an authorized administrator of UBT Knowledge Center. For more information, please contact knowledge.center@ubt-uni.net. 


\title{
Prepaid Meter Management System Challenge for Albanian Power Distribution Operator-OSHEE
}

\author{
Genci Sharko $^{1}$, Anni Dasho Sharko ${ }^{2}$ \\ ${ }^{1}$ Polytechnic University of Tirana, Electrical Engineering Faculty \\ ${ }^{2}$ Europian University of Tirana, Faculty of Economy and Information Technology \\ $\left\{\right.$ gsharko $^{1}$, anidasho $\left.{ }^{2}\right\} @$ gmail.com
}

\begin{abstract}
Based on the currents situation for OSHEE it is necessity to design and implement a new reform for power sector covering in order to reduce distribution losses and improve collection, improve the power market model in line with EU directives and diversify generation source. Implementing of smart systems has been analyzed and implemented partially since former CEZ Albania Company, and for the state owned Company now OSHEE this new technology is highly efficient and can realize the ideas for the development of Smart Systems further. The implementation of SMART Systems will impact the OSHEE Distribution System through the upgrade of the distribution infrastructure and the transmission meter/data center, and the OSHEE Distribution Company-Sales will benefit from the reduction of losses and improved billing and collection rates.
\end{abstract}

Keywords: Smart Metering System, My Avis, Converge, Billing and Collection System, Smart Grid and SCADA System.

\section{Introduction}

The Albanian Power Distribution Operator OSHEE is facing serious financial and operational challenges in Albania manifested by a large unfunded deficit and a large level of technical and commercial losses, due to non-payment of electricity bills by costumers, as well as poor collection rates. Based on the the currents situation for OSHEE its necessity to design and implement a new reform for power sector covering: reduce distribution losses and improve collection, improve the power market model in line with EU directives and diversify generation source.

The idea of implementing Smart Metering Sy stems-Prepaid Metering Project has been analy sed and implemented partially since CEZ Shpërndarje management time, through implementation of the begist Project part of it the following phases:

a. MyAvis,

b. Converge,

c. Prepaid Metering System

Now for the state owned Company now OSHEE this new technology is highly efficient and can realise the ideas for the development of Smart Sy stems-Prepaid Metering Sy stem though a pilot project for some problematic zones in Tirana. The implementation of SMART Systems will influence the OSHEE Distribution System as follow: upgrade of the distribution infrastructure; upgrade the transmission meter/data center; and of the OSHEE Distribution Company-Sales, will benefit from the reduction of losses and improved billing and collection rates.

Is oshee already ready for the prepaid metering revolution? All it is needed to know about the benefits of prepaid meters:

- The smart grids can alleviate the pressure exerted by many of the above-mentioned challenges and create new business opportunities for utilities.

- The major challenges utilities face and will continue facing over the next decade refer to environment, operational efficiency, regulatory compliance, consumer expectations, aging infrastructure, and security. 
- The smart grid concept encompasses a number of initiatives, including smart metering, distribution automation, smart grid communications, home energy management, demand side management, and electric vehicle infrastructure.

This project is a first, necessary step to support sector reforms, leading to improved quality of service and reliability for OSHEE, Kesh and OST main actors in Albania. The reliability of the electrical system (due to under-investment in the infrastructure), growing demand and the increasing difficulty of building new transmission infrastructures are the primary drivers for smart grid implementation system in Albania. "Smart grid" generally refers to a class of technology; people are using to bring utility electricity delivery systems into the 21 st century, using computer-based remote control and automation. These systems are design possible by two-way communication technology and computer processing that have been use for decades in other industries. They are on electricity networks, from the power plants and wind farms all the way to the consumers of electricity in homes and businesses. They offer many benefits to utilities and consumers, mostly seen in big improvements in energy efficiency on the electricity grid and in the energy users' homes and offices.

\section{Implementation of MyAvis/MobiRead and Converge Systems.}

Government of Albania owns through state administration and management the OSHEE-Albanian Distribution System Operator.

During CEZ Group management 2009-2012, CEZ Shperndarje started to meet growing customer expectations by improvingElectricity Quality supplying in Albania and improving Quality Service to Albanian Consumers.

Some of the CEZ Group information systems, which have been re-engineered and developed that time and re-functioning as well even now for OSHEE Company, are:

- "My Avis" and "Converge" sy stems for reading monthly consumption of customers through readers or not readers presence, using the PDA's and MyAvis System or Smart Meters transmmiting in distance(every $15 \mathrm{~min}$ ) data to Converge System calculating the monthly Consumption at Converge system and finalising monthly bill at Billing System.

- $\quad$ The Centralized Billing System

- Data Cleaning Project in closed cooperation with the Management of Looses Project

- $\quad$ Prepaid Meter - Project. (Tirana pilot part with a 2000 customers to be tested.

In the energy sector one of the successful and innovative project by OSHEE will be implementation of an integrated Meter-M anagement Sy stem where by this project the OSHEE will increase the quality and accuracy of the reading and online integration with Billing System.

The MyAvis and Converge project consisted of three main parts.

- Converge System; the system delivers the prerequisites for an automated, end-to-end process - from metering to billing. (Online reading of about 3000 electricity smart meters for big customers)

- MyAvis/MobiRead System (Online reading, through electronic reading devices-PDA's, by the readers)

- Online transmission in both systems implemented using the GPRS network of mobile companies AMC and Vodafone mobile operators.

The previous reading electricity meters system was carried out manually in paper notes records kept by readers for CEZ Shpërndarja/OSHEE customers, and all those data were enter manually through Billing operators at Billing System. This process increase risk of having data redundancy, inaccuracy, insecurity and data entry human error unnecessary overload, and additional workflow for the CEZ employees. 


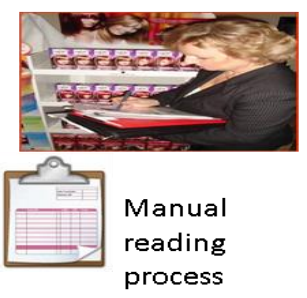

process

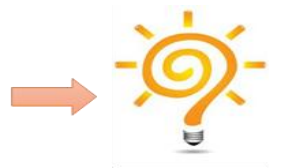

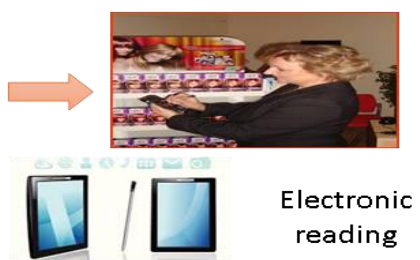

\&

transmissions

Fig. 1. My Avis System, from manual reading to electronic reading and data processing to Billing System.

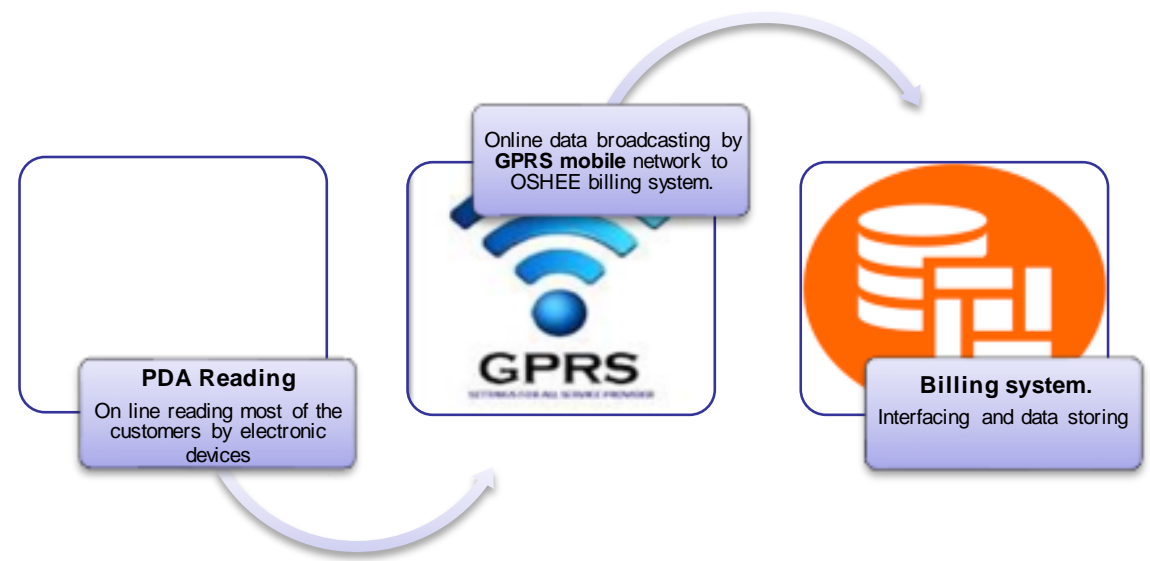

Fig. 2. My Avis System reading process through reader using PDA's and transmitting and interacting data with Billing System

\section{Revolutionary Meter Management System}

Revolutionary of smart metering management system: a. prepaid metering and b. converge metering system have been initiated and implemented partly or not since CEZ Management Time for CEZ Shperndarje, 2010-2012. Now for the OSHEE company needs to be analysed the financing of the biggest project regarding smart metering system for the wholesale electricity market in Albania, using converge metodology, expecially for big and main clients having a very big monthly consumption. The project aim was to modernize all metering facilities of the transmission network in Albania. The benefits and functionality of the smart metering system are:

- one of the most important components of a liberalized electricity market is an extensive commercial metering system,

- the system provides metering data to determine energy/power flows including power losses created by contracts between different market participants,

- it also simulates input from these contracts regarding processing of metering data, which is input information for settlement of contracts between market participants.

The system will covers the following main tasks:

- Measurement of active and reactive energy, at the border of the transmission network

- Evaluation of losses in the transmission network including calculation of losses of each market participant

- Processing of advanced data aggregation taking into account network parameters

- Data handling for estimation of future power consumption

OSHEE continuing defining the prepaid meters as an advanced meter that identifies the electricity consumption pattern in better detail as compared to a conventional meter. 
- Two-way communication - ability to send and receive data from the utility.

- Time of Usage - enable the utility to analyze peak consumption time, bill their customers a premium rate for the peak time usage, and vary the pricing based on demand.

- Outage Detection - detects power outages and fluctuations.

- Key Features - tamper detection, accurate meter readings, power quality monitoring, and remote switch off/on. [3]

Smart meters bring benefits to all stakeholders of the utilities industry, snd the value proposition of smart meters is different for consumers, governments and the utilities.

Consumers will enjoy more accurate billing: Smart meters will facilitate the replacement of consumption estimates, which are a major source of customer complaints. Furthermore, consumers can use smart meters as a tool that helps them to better manage their energy consumption, and thus reduce costs.

Governments could profit from a reduction of resource consumption (water, power) and reduction of $\mathrm{CO} 2$ emissions: In addition, investments in smart metering could represent a moderate stimulus for the economy with the involvement of industry players across deployment projects. The economy could take advantages of these investments. [4]

Utilities can obtain savings from remote reading or remote activation/deactivation of services:

- Additionally, they will have accurate data that could help to develop more efficient billing and load management systems, as well as reduced outage times.

- Maintaining and enhancing this value proposition over time will be difficult, as smart metering projects are carried out in the early stages of smart grids.

- Smart meters must be future-proof, because many variables - such as the regulatory framework or consumer preferences - are likely to change in the future. In addition, the availability of different payment methods is a key feature when designing futureproof smart meters.

The pilot project consist on installing around 53.000 prepaid meters.

- Around of 13.000 prepaid meters will be installed mostly in the territory of Tirana City (in Babrru, Paskuqan and Bathore)

- The rest around 40.000 prepaid meters will be installed all around Albania at the most problematic zones with a very poor collection rates of the invoices, and where the loses are much higher than the rest of the other zones

The overall cost for implementing such a system is based on:

- Cost of prepaid Meters, IT hardware, systems, and applications that enable AMI features and functionalities, and Other AMI related costs need for the implementation of this Pilot Project. Approximate cost was 150-200 euro per consumer.

\section{Smart Meters and Home Energy Management Systems}

Smart meters provide the Smart Grid interface between customers and Albanian Energy Provider OSHEE. Installed in place of our old, mechanical meter, these meters operate digitally, and allow for automated and complex transfers of information between our home and our energy provider. For instance, smart meters will deliver signals from our energy provider that can help us cut our energy costs. Smart meters also provide utilities with greater information about how much electricity is being used throughout their service areas.

This energy information coming to and from our home through our smart meter can be run through a home energy management system (EMS), which will allow the customers to view it in an easy-tounderstand format on your computer or hand-held device. A home EMS allows the customer to track his energy use in detail to better save energy. [5]

EMS also allows us to monitor real-time information and price signals from our utility and create settings to automatically use power when prices are lowest. We can also choose settings that allow specific appliances and equipment to turn off automatically when a large demand threatens to cause an outage-avoiding peak demand rates, helping to balance the energy load in our area, and preventing blackouts. Our utility may provide financial incentives for doing so. 


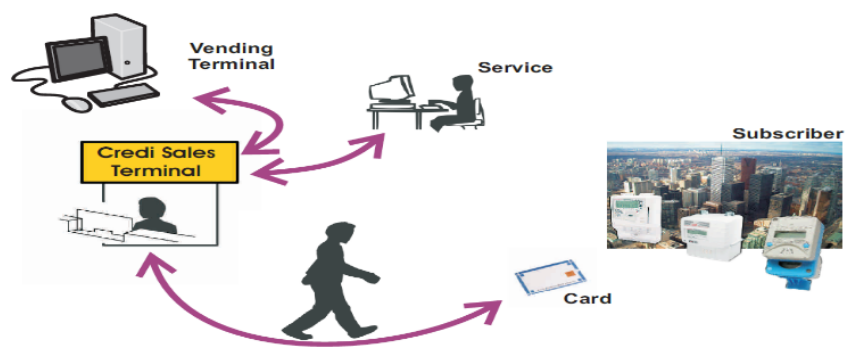

Fig.3. Energy Management System

As consumers move toward home energy generation systems, the interactive capacity of the Smart Grid will become more and more important. The Smart Grid, with its system of controls and smart meters, will help to effectively connect all these mini-power generating systems to the grid, to provide data about their operation to utilities and owners, and to know what surplus energy is feeding back into the grid versus being used on site. A potential feature of the Smart Grid will be to allow our community to use our solar array and our neighbour has to keep the lights on even when there is no power coming from a utility. Distribution Division is developing the project of smart meter installation in all available $10 / 0.4 \mathrm{kV}$ substation. This project is very important to reduce technical and commercial losses. The project is expected to be completed in early 2016.

\section{Conclusion}

Actions to be addressed in Short on the reorganization of the OSHEE Company:

- It is envisaged a full reorganization of the Operational Activities where head responsible of a number of feeders will be in charge of metering, meter reading, irregularities and collection enforcement.

- Clear and transparent objectives shall be assigned to the heads.

- Evaluation of alternative technologies for the management of the commercial cycle in specific cases (Prepayment, Smart Metering, etc.)

- Improvement of regulatory aspects.

- There is a need for some regulatory support in order to facilitate the quick recovery of losses and collection.

- The implementation of the plan shall require specific resources that need to be addressed with the regulator.

The needs of a Quick Wins Project will provides activities that can be quickly implemented and that shall provide quick results to the OSHEE Company. Quick Wins Project needs to be focused on the following steps:

- the establishment of the monitoring framework to ensure the information provided by Meter Readers,

- $\quad$ stabilizing the billing anomalies and start constituting a real Guardian of the Process instead of a Fireman Department,

- customers start or stop billing energy with no proper control and understanding, introducing the values concept in order to start creating 'friends' within the staff.

- Control the energy flow. As of today the control is very weak.

- Start strengthening the meters to make them more reliable and less accessible for 'trickers' the access to the machinery - Today's meters are physically and technically vulnerable and help little to detect irregularities. 
International Conference on Energy Efficiency Engineering, Nov 2015

\section{References}

1. www.landisgyr.com

2. www.cez.cz; www.cez.ro; www.cez.bg;

3. Jackson R.E. and Walton C.M , 2003, "A Case Study of Extensive MV Automations in London”, 17th International Conference on Electricity Distribution CIRED, session 3, paper 36, Barcelona 2003

4. "Siemens", 2002, "Medium-Voltage Switchgear", Catalogues HA 45.31 2000, HA 40.1 2000,

5. Working Group 07 of CIGRE study Committee 34, "The automation of new and existing substations: why and how", CIGRE, 2001

6. "Schneider Electric", "Modular unit for MV/LV transformer substations, industrial distribution, and MW switching" 